\title{
Testing Two Classes of Theories about Group Induced Shifts in Individual Choice ${ }^{1}$
}

\author{
Eucene Burnstein ${ }^{2}$ ANd Amiram Vinokur \\ The University of Michigan
}

\begin{abstract}
One class of theories explains group induced shifts in individual choice in terms of interpersonal comparison process. By comparing himself with others a member finds out that his position is uncomfortably discrepant, e.g., he is overly cautious or overly risky. Knowledge of this discrepancy presumably is necessary and sufficient to induce him to change his initial choice. Another class of theories holds that merely knowing one is different from others is unimportant. Shifts in choice occur because during discussion a member is exposed to persuasive arguments which prior to discussion were not available to him. Two experiments were conducted, the results of which give considerable support to persuasive-argument theories and none to those based on interpersonal comparison: When a member did not know whether others were arguing for their own position or were forced to support a position contrary to the one they had originally chosen, and the former in fact was the case, typical shifts in choice were obtained. However, if a member had to argue for a position contrary to the one he had initially chosen (and thus he would not be able to muster highly persuasive arguments) typical shifts did not occur, even though another's initial choice could be accurately inferred.
\end{abstract}

There is a traditional distinction made in the analysis of interpersonal influence and conformity which has to do with uniformities in belief and behavior due to informational processes versus those due to normative processes (Deutsch \& Gerard, 1955). The former involves the dissemination of knowledge among group members regarding an issue over which they differ. Faced with a collective choice, members inform each other about the merils of their respective position. Information which initially

'This research was supported by a Grant from the National Institute of Mental Health (MH-16950-03) and by a Guggenheim Foundation Fellowship awarded to the first author. We gratefully acknowledge the incisive, witty, and vinous commentary provided by colleagues at the University of Provence, in particular Robert Abelson, Claude Flament, and Jean-Pierre Poitou, as well as the spirited and intelligent efforts of Livia Mezrick and Irene Graczyk, who helped us carry out the study.

${ }^{2}$ Requests for reprints should be sent to Eugene Burnstein, 4136 Institute for Social Research, The University of Michigan, Ann Arbor, MI 48106.

123

Copyright (C) 1973 by Academic Press, Inc.

All rights of reproduction in any form reserved. 
was only partially shared thereby becomes available to all. Consensus is achieved when the shared knowledge is persuasive, when it is sufficient to demonstrate the superiority of one particular course of action. In contrast, normative processes describe the impact of rewards and punishments, actual or anticipated. When a person values his membership in a group and finds his position on an important issue differs from that of other members, he is likely to experience a variety of distressful ('mo)tions-fear of disapproval, of being shaned, of loss in self-esteem, te. The person will then ostensibly abandon his position and shift toward the consensus in order to reduce such threats.

While the distinction between informational and normative processes is not new, its relevance to collective decisions involving "risk" is only now becoming evident. This is the consequence of somewhat overduc attempts to explain such exotic group induced shifts in choice as the "risky" shift in terms of more general interpersonal processes." The present research represents such an effort and considers the informational-normative distinction as basic in understanding these effects.

A few reviews have recently appeared on group induced shifts which raised several important and heretofore neglected points (Cartwright, 1971; Pruitt, 1971a; Vinokur, 1971a). One is especially significant for our purposes. Both Pruitt and Vinokur suggest that the various theories proposed to account for shifts fall into two distinct classes corresponding, we think, to the normative-informational distinction. More precisely, there is a group of theories which asserts that discussion is unnecessary and insufficient to produce shifts in choice. A member merely must recognize that his own position differs (in a specified direction) from others, such realization being sufficient to induce a shift. These theories thus depend on interpersonal comparisons, although only one is cast in terms of classical social comparison theory (see below). A second group of theories assumes exposure to or participation in discussion is both necessary and sufficient. They stress persuasive argumentation and, to some extent, differential influence or leadership based on such argumentation. A brief description will demonstrate that these classes of theories make quite different predictions which are readily testable.

${ }^{3}$ Although "risk" is the usual term of reference in the literature, as is "cautious" or "conservative" for another collection of decisions and their corresponding shifts, it has been clear for some time that the person's response to these items may have little to do with the concept of risk (or caution) either as defined by averyday usage or by decision theory. Merely one exauple: the same kind of group induced shifts have been obtained on issues totally unrelated to risk, such as the individual's evaluation of DeGaulle (Doise, 1969; Gouge \& Fraser, 1972; Moscovici \& Zavalloni. 1969; Myers \& Bishop, 1970, 1971). For convenience sake, however the quntation marks will be omitted in the remaining text. 
The importance of persuasive argumentation in group decision making was noted some time ago by Thorndike $(1938 \mathrm{a}, \mathrm{b})$. It has been variously used to analyze group induced shifts in choice by Nordhøy (1962), St. Jean (1970), Stoner (1968), Teger and Pruitt (1967), Vinokur (1971a,b), and Vinokur and Burnstein (1972). The Vinokur version assumes that a particular decision elicits a set of standard arguments in support of the various alternatives among which the person must choose. Presumably the arguments reflect certain cultural values engaged by the decision. A persuasive argument is thought to be similar in effect to that of a correct solution in group problem solving: once made, it is very likely to be accepted either because it is intrinsically cogent, the member who proposes the argument is highly confident of its merits, or both. These phenomena have been observed and discussed in a variety of group decision and group problem solving situations (Burnstein \& Katz, 1971; Clausen; 1965; Thomas \& Fink, 1961; Thorndike, 1938a,b; Vinokur, 1971a).

The number of arguments available to the average member (or the probability of a particular argument) will vary as a function of the issues raised by the decision. Thus, faced with a particular choice, a very large, a moderate, or an extremely small number of arguments may come to mind. The extent of the shift in choice a group will induce depends on the likelihood that the average member will have available all or most of the persuasive arguments. If the likelihood is very great, then individuals will have already made their initial choice on the basis of all or most of the persuasive arguments. Therefore, not only will they have confidently taken a relatively extreme position beforehand, but they also are unlikely to encounter new persuasive ideas in discussion, ones which had not been considered in making their initial choice. If the likelihood is very small, very few individuals will be able to muster strong support for their position during discussion, and thus hardly anyone will have a good reason for changing their choice. It follows that the largest shifts will be induced by group discussion when persuasive arguments have a moderate likelihood of being available to the average member. ${ }^{4}$

Among the interpersonal comparison theories, Brown (1965), Levinger and Schneider (1969), and Jellison and Riskind (1970) assume that an individual contrasts his choice with the average choice of other members; and they predict, for somewhat different reasons, that relatively moderate choices will be changed so as to be equal to or more extreme than this average. Pruitt (1971a) believes the comparison is made with the most extreme member, to the same effect. The incentive for shifting also varies somewhat from theory to theory. For Brown, the member's

'This analysis owes much to Steiner's work (1966) on the optimum distribution of information in problem solving groups. 
choice reflects his adherence to cherished social values; an immoderately moderate member will change because he wants to demonstrate as much or more adherence than the others. Jellison and Riskind define the choice (of a risk level) as an assertion of ability; because, according to social comparison theory, the person wishes to appear slightly more able than others, a shift in choice will be made by the relatively moderate members. Finally, Levinger and Schneider, as well as Pruitt, think the moderatc member really wants to take an extreme position but initially suppresses this yearning; the observation that others have made extreme choices legitimizes the desire and allows the member to shift with impunity.

Past work on the relative significance of knowledge of other's position and of group discussion had members either discuss without revealing their own choice or reveal their choice without discussing. The former procedure produced sizable shifts (Clark ef al., 1971; St. Jean, 1970). However, reasonably accurate inferences probably could be made abont where another member actually stood from what he said in discussion even without his making an explicit statement to that effect. With the latter paradigm some researchers have observed rather weak shifts (Clark \& Willems, 1969; Teger \& Pruilt, 1967), while nost have foumd no shifts at all (Clark et al., 1971; St. Jean, 1970; Wallach \& Kog:m, 1965). Hence, although there has been a good amount of work on discussion versus knowledge of other's choice, the matter is still unresolved. The present study takes a different approach to this problem. In the first of two experiments a subject knows that on some decisions he must argue for his own position (ambiguous-for condition) and on others hec must argue for the opposite (ambiguous-against condition). He is aware that this is true for the other members as well. However, on any given decision he does not know who is permitted to argue for their own choice and who is obliged to support some other position. Thus. a subject's own position cammot be inferred from what he says. The second experiment consists of only one condition (unambiguous-against); its control would merely replicate the standard paradigm for shift in choice. In this experiment any subject can preciscly determine anothers real preference because it is always the exact contrary of what he advocates during group discussion.

The theories based on interpersonal comparison predict no shift in choice as long as members remain ignorant of each other's real preference; typical shifts will occur, however, when such knowledge becomes available, independent of discussion. In the first experiment the person never knows who is arguing for or who is arguing against their actual preference. Thus according to interpersonal comparison theories, there should be no group induced shift in choice. In the second experiment. 
because a member's real preference can be readily determined (even though it is contrary to the position he advocates in discussion), the typical shifts toward risk and toward caution should be observed. Persuasive-argument theory leads one to expect almost the opposite results. Note that this theory assumes the individual will initially choose the alternative for which he has the greatest number of persuasive arguments. Hence, when asked to support a position which he had previously rejected (in the ambiguous-against and unambiguous-against conditions), the person is being required to advocate what for him is relatively unadvocable, that is, to take a position for which he has few persuasive arguments. It follows that persuasive argumentation is less likely to occur in these circumstances than under conditions in which the individual is free to advocate his initial choice (ambiguous-for). According to persuasive-argument theory, this means that little or no shift should be expected in either the ambiguous-against or the unambiguousagainst situation; typical shifts, however, will occur when individuals argue for their initial choice (ambiguous-for) even when they cannot infer another's real preference, that is, they do not know whether he is advocating his own position or one quite different.

Finally, keep in mind that obliging the subjects to argue against their own position allows the possibility of certain celebrated counter-attitudinal phenomena. These have little to do with the theories under consideration; in fact, they are beyond the scope of either. Changes in choice resulting from counterattitudinal processes, e.g., dissonance reduction, would, in fact, create atypical shifts in choice, opposite in direction from those normally obtained with these decisions. Shifts of this nature are predicted neither by interpersonal comparison nor by persuasive argumentation. They therefore have little bearing on the issue at hand.

\section{EXPERIMENT I}

\section{Method}

Subiects. A total of 149 male students from introductory courses in psychology at The University of Michigan participated as subjects in this experiment. Participation was part of the course requirements. Each experimental session lasted for an hour. The subjects were run in 21 five-man groups and 11 four-man groups, making a total of 32 groups.

Material. A set of five items were taken from the Kogan and Wallach (1964, appendix E) Choice Dilemma Questionnaire (CDQ). These were assembled in a booklet which was entitled "Opinion Questionnaire."

The CDQ items were chosen to include two risky items (items that have been found to yield reliable risky shifts), two conservative items (items that have been found to yield reliable conservative shifts), and one neutral item (an item that has 
been found to yield no consistent significant shift). These items (numbers 4, 6, and 2 in the CDQ) begin with Mr. A, Mr. B (risky items), and $\mathrm{Mr} . \mathrm{H}$ (neutral item) in our questionnaire. The two cautious items, Mr. E and Mr. F, were taken from a questionnaire used by Stoner (1968; numbers 2 and 8 , respectively, in his questionnaire). These five items were also used by Vinokur (1971b) in a set of experiments in which the typical findings were replicated.

Each choice-dilemma was accompained by the standard instructions to choosebetween odds of $1,2,3,4,5,6,7,8$, or 9 chances in 10 -the lowest odds of success acceptable in order to recommend trying the uncertain (risky) alternative; or, instead, to indicate that this alternative should not be attempted, no matter what the odds. In the latter case, a response is usually scored as 10 . Choice of risk level is measured as the odds that are selected by the subject.

Procedure. Subjects sat at small tables when they arrived at the laboratory and filled out the Opinion Questionnaire at their own rate. The questionnaires were then collected and subjects performed an anagram task as interpolated activity for about $10 \mathrm{~min}$ while assistants coded their answers to the CDO items and prepared materials for the experimental manipulations which were introduced immediately before group discussion. Following interpolated activities, subjects were given clean copies of the Opinion Questionnaire. They were then informed in order to be sure a wide variety of positions were represented in the discussion they would be told privately by the experimenter, beforehand, what position to take. It was pointed out that often the position they were given to support would be contrary to the one they had initially chosen. Finally, the experimenter stressed that the subjects were to argue as effectively as possible for the position given to them and that although they were to explicitly state this position at the start of the discussion, they were to refrain from giving any indication of whether or not it corresponded to their initial choice."

It was made clear that the discussion on each CDQ item was to last for 5 min and that the experimenter will indicate when to begin and when to end the discussion before moving to the next item. Just before the first discussion each subject received a slip indicating the position he was to take in every item. The position was stated in the usual "chances out of 10 " and varied in a predetermined way over jtems (see below).

Experimental manipulations. The CDQ items were arranged in the questionnaire in the following order: Mr. B, F, H, A, E. Items which typically give risky and cautions shifts were thus alternated. In half the grouns, subjects were assigned a position contrary to their choice on the first Opinion Questionnaire for items B, H, and $\mathrm{E}$, and a position identical to their initial choice for items $\mathrm{F}$ and $\mathrm{A}$. In the other half of the groups, subjects were assigned contrary positions on items $F$ and $A$, and identical positions on items B, H, and E. Note by "contrary" is meant the mirrorimage of the subject's initial scale position; thus, an initial choice of 1,2,3, or 4 out of 10 was assigned $9,8,7$, and 6 out of 10 , respectively, and vice versa. Half of the subjecls who inilially chose 1 were assigned 9 and half were assigned 10 out of 10. An initial choice of 10 out of 10 , which meant that the uncertain alternative should not be chosen no matter the odds, was always assigned 1 out of 10 ; and 5 out of 10 remained unchanged. Unknown to the subjects, on each item either they were all assigned a position which was contrary to their own choice, or they were all assigned a position which was identical to their own choice. Thus, although each

"Verbatim instructions are available from the authors upon request. 
subject knew whether he argued for his own position or not, he could not know this for the others. In fact, the manipulations sought to create the impression that positions were randomly assigned.

The experimental conditions are not based on data from different groups but on data from the same groups on different CDQ items. Instances in which subjects argued for their initial choice constitute the ambignons-for conditions; instances in which they were obliged to argue for a position contrary to their initial one constitute the ambiguous-against condition.

After the discussions of all the items were completed, each subject was asked to reconsider and to mark what he now felt to be the best decision.

Finally, subjects were asked to indicate whether (a) everybody in his group argued for his position, (b) against his own position, (c) some for and some against, or (d) do not know. This was done separately for each CDQ item. When this was completed, subjects were given a full explanation of the experiment and its purpose.

\section{Results}

There is no evidence that subjects could reliably infer another's initial choice from the position he advocated during discussion. In instances where every member argued for his initial choice (ambiguous-for condition) only $23 \%$ indicated they felt this to be the case; $3 \%$ indicated that they felt everyone was arguing against his initial choice; $59 \%$ indicated they felt that some argued for and others argued against their initial choices, and 15\% indicated they could not tell. In instances where every member argued against his initial choice (ambiguous-against condition) only $15 \%$ indicated they felt this to be the case; $10 \%$ indicated they felt everyone was advocating his initial choice and $63 \%$ and $12 \%$ indicated they felt some argued for and others argued against their initial choice or they could not tell. Given four response categories, $23 \%$ of correct responses (i.e., responses indicating correct identification of the experimental situation) in ambiguous-for condition and 15\% of correct responses in the ambiguous-against condition are well below chance. Moreover, internal analysis of the shifts produced by the subjects who correctly inferred the relationship between initial and advocated choice showed that they were not different from the shifts produced by the other subjects. In all cases the shifts of the correct subjects were in the same direction as the shifts of the other subjects, and in no case was the difference statistically significant. Indeed, in most cases, contrary to what would be predicted by interpersonal comparison theories, the shifts of the correct subjects were smaller in magnitude than the shifts of the other subjects.

The major results for shifts in choice are presented in Table 1.

Under ambiguous-for conditions both risky items give reliable shifts; one cautious item produces a highly reliable shift while the other gives a 
TABLE 1

Mran Individual Choice Beforf $\left(p_{1}\right)$ and After $\left(p_{2}\right)$ Discussion and Mhan ShJfts for Groups $(d)$ After Discussion Under

Two Conditions of Ambigeity

\begin{tabular}{|c|c|c|c|c|c|c|c|c|c|}
\hline & \multicolumn{4}{|c|}{ Individuals } & \multicolumn{5}{|c|}{ Groups } \\
\hline & & & & & & $d^{h}$ & & & \\
\hline & Items & $N$ & $p_{2}{ }^{n}$ & $p_{l}^{a}$ & 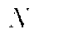 & Shift & $\mathrm{AD})_{t}$ & $t$ & $y^{\prime}$ \\
\hline \multirow{9}{*}{$\begin{array}{l}\text { Condition } \\
\text { Ambiguous-for }\end{array}$} & Risky & & & & & & & & \\
\hline & $\mathrm{A}$ & 77 & 3.36 & 4.17 & 16 &.$- \$ 3$ & $0.6 \times 1$ & -4.704 & .(1)1) 1 \\
\hline & B & 72 & 5.42 & 5.76 & 16 & -.33 & 0.531 & -2.531 & .05 \\
\hline & $\begin{array}{c}\mathrm{A}+\mathrm{B} \\
\text { Cantions }\end{array}$ & 149 & 4.35 & 4.94 & 32 & -.59 & 0.651 & -5.060 & (0) \\
\hline & $J$ & 72 & 8.42 & 7.76 & 16 & $6 x$ & 0.489 & 2.452 & 111 \\
\hline & $\mathrm{F}$ & 77 & 8.56 & 8.36 & 16 & .20 & 0.554 & 1.397 & $\cdots$ \\
\hline & $\mathrm{E}+\mathrm{F}$ & 149 & 8.49 & $\therefore .07$ & 32 & .44 & $01.77 !$ & 3135 & .111 \\
\hline & Neutral & & & & & & & & \\
\hline & $\mathrm{H}$ & 72 & 7.26 & 6.87 & 16 & .41 & 0.697 & $2.26 \overline{7}$ & (1)i \\
\hline \multirow{9}{*}{$\begin{array}{l}\text { Condition } \\
\text { Ambiguous- } \\
\text { against }\end{array}$} & Risky & & & & & & & & \\
\hline & A & 72 & 4.36 & 4.21 & 16 & .13 & 1.050 & 0.481 & $\cdots$ \\
\hline & B & 77 & 5.43 & 5.61 & 16 & -.111 & 0.765 & -0.945 & \\
\hline & $A+B$ & 149 & 4.91 & 4.93 & 32 & -.03 & (1).92!) & -0.167 & \\
\hline & Cautious & & & & & & & & \\
\hline & $\mathrm{I}$ & 77 & 7.49 & 7.14 & 16 & .35 & 1.350 & 1.003 & \\
\hline & $\mathrm{F}$ & 72 & 8.10 & 8.32 & 16 & -.23 & 1. 161 & -0.760 & $\cdots$ \\
\hline & $\begin{array}{c}E+F \\
\text { Neutral }\end{array}$ & 149 & 7.79 & 7.71 & 32 & $.06 i$ & 0.898 & 1). 262 & \\
\hline & $\mathrm{H}$ & 77 & 5.79 & 6.74 & 16 & -.90 & 1.064 & -3.28 .5 & $(11$ \\
\hline
\end{tabular}

"The value of $p$ indicates the risk-level chosen in terms of $p$ chances unt of ten. A $p$ of :3 would denote the choice of three chances ont of ten as the minimum acceptable probitbility of success on the uncertain outcome.

${ }^{b} d=p_{2}-p_{1}$; negative values indicate shifts toward risk (risky shift).

" $p$ for two-tail $t$ test.

shift which approaches but does not quite reach traditional levels of statistical significance. There is no sign of such shifts in the ambiguousagainst condition. A comparison between the overall shift on risky items $(A+B)$ under the two experimental conditions reveals that the magnitude of the shift is reliably greater in ambiguous-for than in ambiguousagainst $\left(t=2.768, P_{t}<.01\right)$; a comparison between the overall shifts on cautious items $(E+F)$ gives a similar difference but at a less robust level of statistical significance $\left(t=1.775, P_{t}<.10\right)$.

Unexpectedly, shifts were obtained on the neutral item, toward caution under ambiguous-for and toward risk under ambiguous-against conditions. Neither persuasive-arguments nor interpersonal comparison would pre- 
dict these effects. They are curious findings and defy straightforward explanation. However, since they weigh neither for nor against the theories in question, we will merely note their occurrence and not venture to speculate as to their cause.

On the whole, it is clear that the first experiment gives reasonably strong support to persuasive-argument theory and no support at all to interpersonal comparison.

\section{EXPERIMENT II}

\section{Method}

Subjects. A total of 76 male students from the introductory courses in psychology at The University of Michigan participated as subjects in this experiment as part of their course requirements. Each experimental session lasted for about an hour. The subjects were run in 12 five-man groups and 4 four-man groups, a sum of 16 groups.

Procedure. The procedure was identical to that of the previous experiment up to the administration of the first set of instructions. At this point the experimenter told the subjects that cach time they would all be arguing for a position which was contrary to the one they had chosen initially. Several examples were given of "contrary positions," e.g., if 2 in 10 was initially chosen, then the subject would have to argue for 8 in 10 , if 4 in 10 then 6 in 10 , etc., so that the mirror-image principle was clear and they could readily determine another's initial choice from the position he supports in discussion. As in the first experiment, subjects were asked to be explicit about the position they argued for at the outset and to argue as effectively as possible.

The remaining procedures were again identical to those of the first experiment.

\section{Results}

The findings from this experiment are presented in Table 2. Again the curious shift on the neutral item which, again, we will merely note. Neither risky item alone demonstrates a reliable shift; for both items combined there is some evidence of a shift, albeit quite weak. In absolute magnitude it is less than half the size of the shift obtained in the first experiment with the identical items under ambiguous-for conditions. Statistical analysis also indicates that it is reliably less $(t=1.968$, $\left.P_{t}<.07\right)$. While there is stronger evidence for shifts on the cautious items, they all are in the wrong direction. That is to say, these mildly reliable changes in choice suggest the atypical shifts which were mentioned earlier as often associated with counterattitudinal behavior and as such are not considered to be group induced. Consistent with persuasive-argument theory, the typical shift for both cautious items combined under ambiguous-for conditions is considerably greater than that under unambiguous-against conditions $\left(t=4.601, P_{t}<.001\right)$. Once again, there is virtually no support for theories of interpersonal comparison. 
TABLE 2

Mean Individual Choice Before $\left(p_{1}\right)$ and After $\left(p_{\text {g }}\right)$ Discussion and Mhan SHift yor Group $(d)$ After Disctision Under

Unambiguous Condition

\begin{tabular}{|c|c|c|c|c|c|c|c|c|}
\hline \multicolumn{4}{|c|}{ Individuals } & \multicolumn{5}{|c|}{ Groups } \\
\hline Items & $N$ & $p_{2}{ }^{a}$ & $p_{1}^{a}$ & $N$ & $\begin{array}{c}d^{b} \\
\text { shift. }\end{array}$ & SI, & $t$ & $p^{c}$ \\
\hline \multicolumn{9}{|l|}{ Risky } \\
\hline A & 76 & 3.83 & 4.07 & 16 & -.24 & 0.789 & -1.149 & - \\
\hline $\mathrm{B}$ & 76 & 5.11 & 5.43 & 16 & -.26 & 0.654 & 1.552 & \\
\hline$A+B$ & 152 & 4.47 & 4.75 & 32 & -.25 & 0.725 & -1.906 & .10 \\
\hline \multicolumn{9}{|l|}{ Cautious } \\
\hline $\mathrm{E}$ & 76 & 7.12 & 7.72 & 16 & -.63 & 1.283 & -1.894 & 10 \\
\hline $\mathrm{F}$ & 76 & 8.04 & 8.31 & 16 & -.29 & 0.826 & -1.376 & \\
\hline $\mathrm{E}+\mathrm{F}$ & 152 & 7.58 & 8.02 & 32 & -.46 & 0.759 & -2.349 & $(15$ \\
\hline \multicolumn{9}{|l|}{ Neutral } \\
\hline $\mathrm{H}$ & 76 & 6.68 & 7.34 & 16 & -.65 & 0.968 & -2.598 & .05 \\
\hline
\end{tabular}

${ }^{a} P$ indicates risk-level chosen in terms of chances out of ten.

${ }^{\circ} r l=p_{2}-p_{1}$; negative values indicate shifts toward risk.

${ }^{c} p$ for two-tail $t$ test.

\section{Discussion}

Theories of interpersonal comparison attribute shifts in individual choice to normative processes-the anticipation of disapproval and loss of pride or self-esteem were one to maintain his discrepant positionwhich comes into play once the discrepancy is known. Because knowledge of other's position is the essential element, it must then be that if a member does not know where his colleagues stand, changes in initial choice cannot be induced, and if he does know, such changes can and will occur. The results of both experiments give no support to this point of view. Group induced shifts were obtained when little or no information was available as to the real position of other members (ambiguousfor), that is, under conditions in which not only were members prohibited from announcing their initial choice but also, they were aware that the latter could well be quite different from what they were obliged to advocate in discussion. Moreover, where it was clear that the choice a member announced and defended in discussion was mirror-image of his real position, which thus could be calculated, typical shifts in choice were not induced (unambiguous-against).

These findings are, however, fully consistent with the point of view that this widely studied group decision situation is governed by informational processes as specified by persuasive-argument theory, according to which knowledge of other's choice has little significance and the shifts 
typically obtained are the result of persuasive argumentation during discussion. Vinokur (1971a,b) has conjectured that a specific decision will engage a set of standard arguments that vary in their persuasivesness and in their availability to the average number. A member's initial choice is determined by the number and the persuasiveness of arguments which come to mind as he weighs the decision. Thus, the extent to which a member commits himself to a particular alternative reflects the easy availability of many persuasive arguments in favor of the alternative. At the same time, of course, it is an indication that persuasive arguments in favor of the nonchosen alternative are difficult to come by. Thus, when (a) the decision elicits persuasive arguments which predominantly favor a particular alternative, (b) there is a moderate probability of such arguments being available to the average member, and (c) members are free to argue for their own choice, as is ordinarily the case, shifts in choice will occur following group discussion. The first two conditions above need not concern us here. In part, their rationale was suggested earlier and a detailed presentation appears elsewhere (Vinokur, 1971a,b). The significance of the final condition is perhaps rather obvious. Because initial choice indicates the position for which a member has a relatively large number of persuasive arguments available, to require that he argue for the contrary position insures rather impoverished, that is, unpersuasive, argumentation. Therefore, in terms of our two experiments, persuasive-argument theory would lead one to expect typical shifts in choice following discussion regardless of whether the positions of others are known, if the person is permitted to advocate his initial choice. Typical shifts are unlikely to occur, however, when the person is constrained to argue for a position other than his own.

These expectations are reasonably well confirmed, although in general the shifts are smaller than those found in other studies, e.g., on the average they are slightly more than half the size of those obtained by Vinokur (1971b). This might suggest two or more processes at work (Pruitt, 1971b), that ordinarily both interpersonal comparison and persuasive argumentation operate to produce the typical shifts toward risk or caution. By excluding one of these components, naturally, we obtain a weaker effect. The two-process explanation would also lead us to expect relatively small but reliable risky and cautious shifts in the second experiment where persuasive argumentation was minimized but interpersonal comparison was distinctly possible. In general, such shifts were not observed. There is, however, another possible explanation of why attenuated shifts would be likely to occur in the present study. This explanation seems quite plausible and, moreover, assumes only one process at work, persuasive argumentation. Briefly, if a member believes others are arguing for a position which they do not really hold, he 
treats their arguments with heightened skepticism. In other words, our experimental treatment probably reduces somewhat the credibility (and thus the persuasiveness) of the argumentation. Because the arguments lose their usual force, the shifts in choice are necessarily attenuated. It seems unnecesary, therefore, to invoke interpersonal comparison processes (or the lack of such) to account for the attenuation of the shift.

Finally, let us briefly attempt to clarify those curious shifts on cautious items in the second experiment. It is well-known that getting a person to aclvocate a position contrary to what he believes (i.e., to engage in counterattitudinal behavior) may lead him at least partly, to accept the position he advocates (for example, sec Carlsmith, Collins, \& Helmreich, 1966; McGuire, 1969). In the present study (ffects of this type would appear as atypical shifts. The reason for this is simple. It has becn established that CDQ-like items which give shifts toward a particular extrenc, say toward risk, also elicit initial choices which in genoral tend to fall toward that end of the scale, to be somewhat risky, for example. Thus, members initially find odds of slightly less than five out of ten as acceptable on items which subseguently produce at shift toward risk and adds of more than five out of ten on items which subsecpuently produce a shift toward caution (see Cartwright. 1971; and as a case in point notice this holds for most values of $p_{1}$ in Tables 1 and 2 ). When individuals are required to argue against their initial choice this means that on risky items most would be arguing for cantion, and vice versa on cautious items. Because of dissonance reduction or some comparable process, if they accepted the arguments they were induced to make, then a cautious shift would appear on typically risky items and a risky shift, on typically cautious items.

While members argued against their own choice in both experiments. such atypical shifts accurred, however, only in the second. This is not totally inexplicable. In their scarch for the conditions which are most likely to produce changes in attitude following counterattitudinal behavior Carlsmith, Collins, and Helmreich (1966) indicate that the likelihood is greater when there is public knowledge of the counterattitudinal act. Such public knowledge was a salient feature of the unambiguousagainst condition. Under ambiguous-against or ambignous-for conditions. it was not possible for any member to know whether another was advocating his real position or its contrary.'

"The atypical shifts do not appear as readily explained by incentive or selfpersuasion theory as by dissonance theory. The former would seem to demand that shifts occur in both experiments, whenever members engage in counterattitudinal behavior. McGuire (1969) makes an excellent comparison of these two theories and points out a large number of loopholes whereby findings of this kind may be safely reinterpreted within either context. 
Still, why is there no sign of an atypical shift for risky items in the second experiment? A dissonance reduction explanation would require a shift toward caution in this case. An examination of the average initial choices ( see $p_{1}$ in Table 2), however, suggests how counter-attitudinal effects might well have been more marked for cautious than for risky items, to wit: in terms of their distance from the scale midpoint (five chances out of ten), initial choice $\left(p_{1}\right)$ on the former is more extreme than on the latter. According to our procedure for assigning a contrary position, the scale was pivoted about the midpoint with an initial choice of four out of ten being assigned six out of ten (and vice versa), three out of ten being assigned seven out of ten (and vice versa), etc. Thus, for cautious items, on the average, the position to be argued was quite contrary to the initial position, a difference of about six scale points between initial and argued choice-from eight out of ten to two out of ten for item $\mathrm{E}$ as well as item $\mathrm{F}$. Not so with the risky items. A difference between initial and argued choice of about two scale points obtained, from four out of ten to six out of ten for item $\Lambda$, and virtually no difference existed for item B. The implication is clear. Greater dissonance could well have been produced on cautious than on risky items because the advocated positions were more incompatible with initial choice in the former than in the latter case. It follows that greater dissonance reduction and, thereby, a relatively marked atypical shift should have occurred on cautious items.

\section{REFERENCES}

Brown, R. Social Psychology. Free Press of Glencoe, New York: 1965.

Burnstein, E., \& Katz, S. Individual commitment to risky and conservative choices as a determinant of shifts in group decisions. Journal of Personality, 1971, 39, 564-580.

Carlsmith, J. M., Collins, B., \& Helmreich, R. L. Studies in forced compliance: I. The effect of pressure for compliance on attitude change produced by face to face role playing and anonymous essay writing. Journal of Personality and Social Psychology, 1966, 4, 1-13.

CArtwright, D. Risk taking by individuals and groups: An assessment of research employing choice dilemmas. Journal of Personality and Social Psychology, 1971, 20, 361-478.

Clank, R. D., Crocketr, W. H., \& Archer, R. L. Risk as value hypothesis: The relationship between perception of self, others, and the risky shift. Journal of Personality and Social Psychology, 1971, 20, 425-429.

Clark, R. D., \& WILlems, E. P. Where is the risky shift? Journal of Personality and Social Psychology, 1969, 13, 215-221.

Clausen, G. S. T. Risk taking in small groups. Doctoral dissertation, The University of Michigan, 1965.

Deutsch, M., \& Gerard, H. G. A study of informational social influences upon individual judgment. Journal of Abnormal and Social Psychology, 1965, 51, 629-636. 
Dorse, W. Intergroup relations and polarization of individual and collective judgments. Journal of Personality and Social Psychology, 1969, 12, 136-143.

Govge, C., \& Fraser, C. A further demonstration of group polarization. European Journal of Social Psychology, 1972, 2-1, 95-97.

JELLIson, J. M., \& Riskind, J. A social comparison of abilities interpretation of risk taking behavior. Journal of Personality and Social Psychology, 1970, 15, $375-390$.

Kogan, N., \& Wallach, M. A. Risk taking: A study in cognition and personality. New York: Holt, Rinehart and Winston, 1964.

Levinger, G., \& Schnemer, D. J. A test of the risk is a value hypothesis. Journal of Personality and Social Psychology, 1969, 11, 165-169.

McGuire, W. J. The nature of attitudes and attitude change. In Lindzey, $\left(C_{\text {., }}\right.$ Aronson, E. (Eds.), The handbook of social psychology. Reading: AddisonWesley, 1969. Vol. 3, 2nd ed.

Moscovici S., \& Zavalioni, M. The group as a polarizer of attitudes. Journal of Personality and Social Psychology, 1969, 12, 125-135.

Myens, D. G., \& Bishop, G. D. Discussion effects on racial attitudes. Science, 1970 , $169,778-779$.

Myers, D. G., \& Bishop, G. D. Enhancement of dominant attitudes in group discussion. Journal of Personality and Social Psychology, 1971, 20, 386-391.

Nornfrgy, F. Group interaction in decision-naking under risk. Unpublished master's thesis, School of Industrial Management, Massachusetts Institute of Technology, 1962.

Pruitt, D. G. Choice shifts in group discussion: An introductory review. Journal of Personality and Social Psychology, 1971, 20, 339-360,a.

Prurtr, D. C. Conclusions: Toward an understanding of choice shifts in group discussion. Journal of Personality and Social Psychology, 1971, 20, 495-510, b.

STEINER, I. Models for inferring relationships between group size and potential group productivity. Behavioral Science, 1966, 11, 273-282.

Sr. JEAN, R. Reformulation of the value hypothesis in group risk taking. Proceedings of the 78th Annual Convention of the American Psychological Association, 1970 , 5, 3.39-340.

Stower, J. A. F. Risky and cautious shifts in group decisions. The influence of widely held values. Journal of Experimental Social Psychology, 1968, 4. $412-459$.

Tegier, A. I., \& PrurtT, D. G. Components of group risk taking. Journal of Experimental Social Psychology, 1967, 3, 189-205.

Thomas, E. J., \& Fink, D. F. Models of group problem solving. Joumal of Abnormal and Social Psychology, 1961, 63, 53-63.

Thorndike, R. L. The effect of discussion upon the correctness of group decisions, when the factor of majority is allowed for. Journal of Social Psychology, 1938. 9, 343-362, a.

Thorndixe, R. L., On what type of task will a group do well? Journal of Abnormal and Social Psychology, 1938, 33, 409-113, b.

VinokUr, A. Review and theoretical analysis of the effects of group processes upon individual and group decisions involving risk. Psychological Bulletin, 1971, 76, 231-250, a.

Vinokuk, A. Cognitive and affective processes influencing risk-taking in groups: An expected utility approach. Journal of Personality and Social Psycholugy, 1973, 20, $472-486, b$. 
Vinokur, A., \& Burnstein, E. The effects of partially shared persuasive arguments on group induced shifts: A group problem solving approach. Unpublished manuscript, The University of Michigan, Research Center for Group Dynamics, 1972.

Wallach, M. A., \& Kogan, N. The roles of information, discussion, and consensus in group risk taking. Journal of Experimental Social Psychology, 1965, 1, 1-19.

(Received May 4, 1972) 